\title{
Comparison between the structure and function of chloroplasts at different levels of willow canopy during a growing season
}

\author{
E. Vapaavuori ${ }^{1}$, A. Nurmi ${ }^{2}$, H. Vuorinen ${ }^{1}$ and T. Kangas ${ }^{1}$ \\ 1 The Finnish Forest Research Institute, Suonenjoki Research Station, SF-77600 Suonenjoki, and \\ 2 University of Helsinki, Department of General Botany, SF-00710 Helsinki, Finland
}

\section{Introduction}

Light climate has a strong impact on the ultrastructure of chloroplasts. There is plenty of evidence that the degree of grana stacking in chloroplasts of plants grown in high light is less than in plants grown in low light (e.g., Lichtenthaler et al., 1981), which is also the case for plants adapted to sunny or shady habitats (Boardman, 1977; Aro et al., 1986). Very little is, however, known about the seasonal acclimation process of the photosynthetic apparatus in the canopy, where leaves that are initially exposed to full sunlight are transferred through half-shade into full shade. In conditions, under which water and nutrient availability are not limiting growth, the shaded leaves remain intact for most of the growing season. This suggests that the leaves retain a positive carbon balance by acclimating to the changing light climate. In this study, we quantified the seasonal changes in the chloroplast ultrastructure at several heights of a willow (Salix cv. Aquatica gigantea) canopy. We also determined how changes in chloroplast ultrastructure fit with their function by measuring the rate of gas exchange under the prevailing environmental conditions in the canopy.

\section{Materials and Methods}

The willow stand (established in $1980,125 \mathrm{~m}^{2}$ in area) was cut down before the growing season 1986 and measurements were made on leaves that emerged on new shoots successively throughout the growing season. The stand was fertilized with a commercial fertilizer ( $\mathrm{Pu}$ utarhan Y-lannos 10-16-17) once a week during the growing season, so that it received a total of $150 \mathrm{~kg}$ of $\mathrm{N} / \mathrm{ha} / \mathrm{season}$. The stand was watered regularly to assure that the plants were not water-stressed.

The samples for electron microscopic examination were taken from 3 replicate plots at 6 different dates from upto 5 different heights (Fig. 1A). The samples were treated as described by Vapaavuori (1986) and Aro et al. (1986). The grids were examined on a Jeol $100 \mathrm{~B}$ electron microscope. Before prefixation of the samples for electron microscopy, the photosynthetic capacity of the leaves was measured at prevailing light and temperature conditions by means of a $\mathrm{CO}_{2}$ porometer (ADC LCA-2, the Analytical Development Co. Ltd., U.K.). The chloroplast 

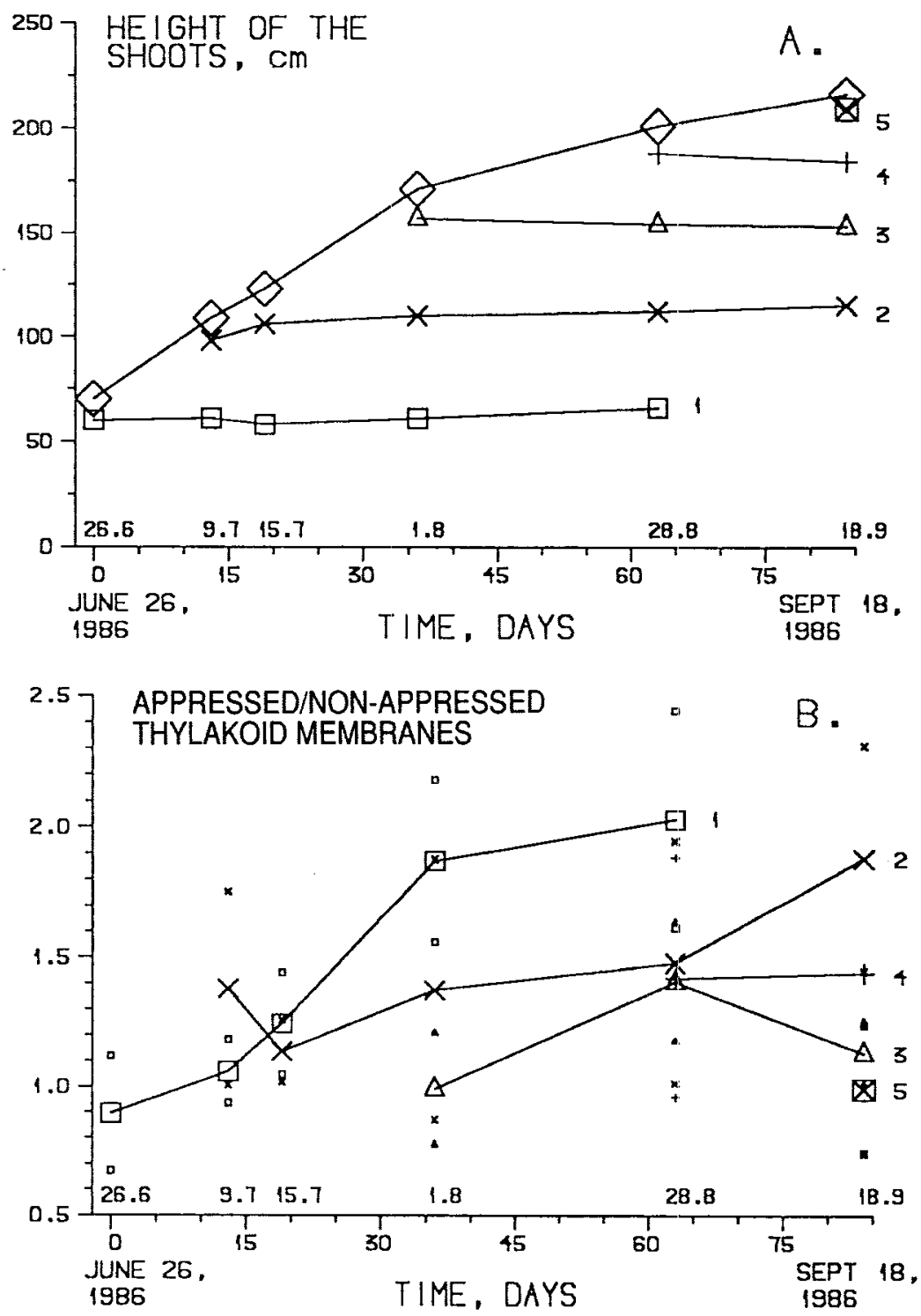

Fig. 1. A. Growth of willow shoots during the growing season. B. The ratio of total length of appressed to nonappressed thylakoid membranes vs time. The numbers $1-5$ show the heights at which the samples were collected.

ultrastructure was analyzed from the electron micrographs as described by Aro et al., (1986) and Vapaavuori (1986). On an average, 6 typical chloroplasts were analyzed from each sample of the 3 replicate plots.

\section{Results and Discussion}

At all studied levels of the canopy, the ratio of the total length of appressed to 
non-appressed thylakoid membranes was lowest $(0.9-1.4)$ in the youngest leaves (Fig. 1B) that were exposed to sun (Fig. 2B). The thylakoid structure in these leaves was similar to that in plants adapted to sunny habitats or grown at high quantum flux densities (Anderson and Osmond, 1987). At level 1 (60 cm aboveground) the ratio increased slightly until the middle of July (Fig. 1B), but remained typical of sun-exposed leaves (below 1.3). During this period, the low rates of $\mathrm{CO}_{2}$
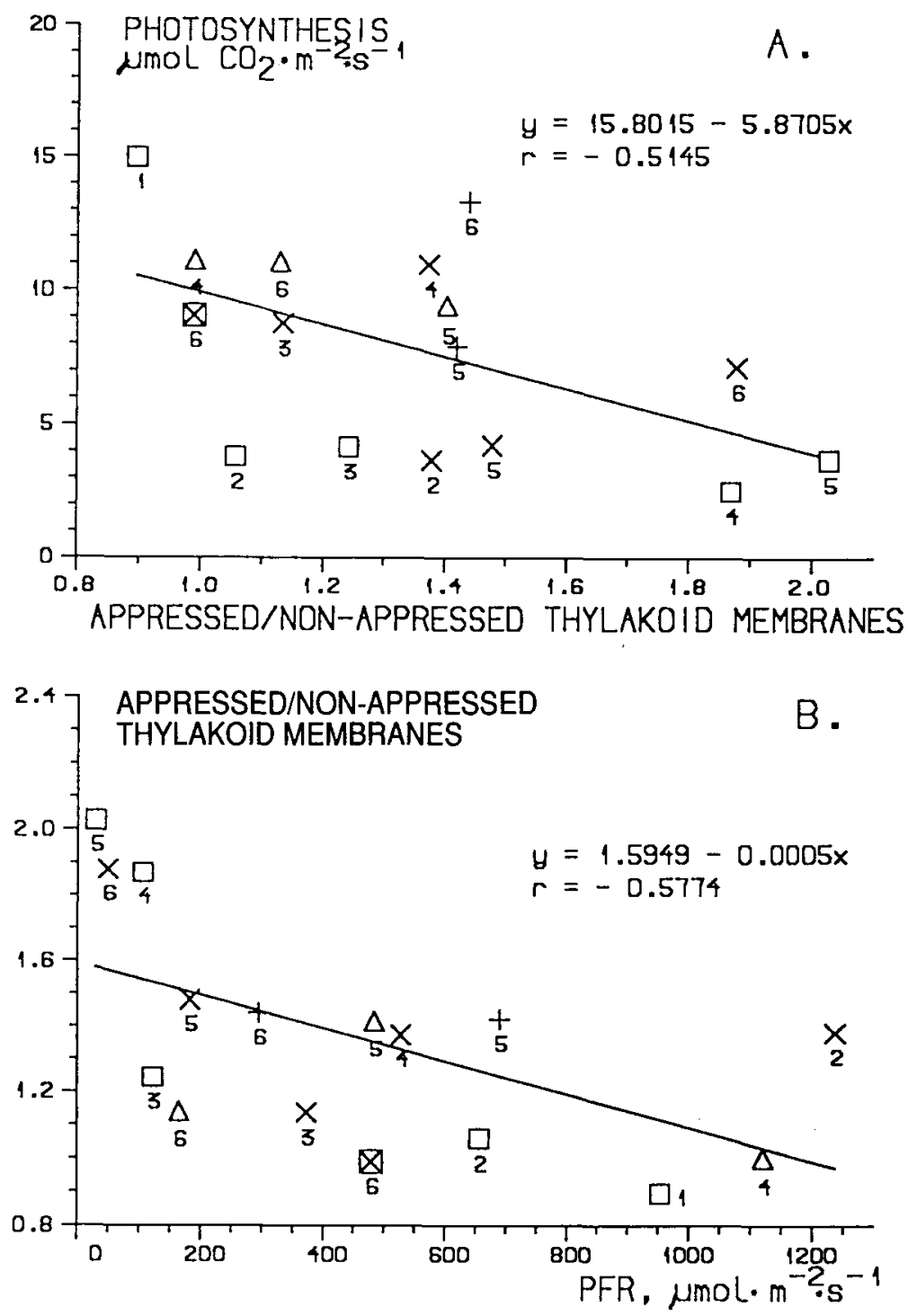

Fig. 2. A. Rate of $\mathrm{CO}_{2}$ uptake vs the ratio of total length of appressed to non-appressed thylakoid membranes. B. Ratio of total length of appressed to non-appressed thylakoid membranes vs photon fluence rate (PFR). Symbols as in Fig. 1A. The numbers $1-6$ refer to the sampling dates in Fig. 1. 
uptake recorded (Fig. 2A) were possibly caused by decreased availability of excitation energy in the canopy and not by altered organization of thylakoid membranes. Later in the growing season, the chloroplast ultrastructure acclimated to decreased light (Fig. 2B) and the low rates of $\mathrm{CO}_{2}$ uptake (Fig. 2A) were possibly caused by altered thylakoid structure typical of shade plants (Lichtenthaler et al. 1981). Part of this reorganization in thylakoid membranes might also be due to ageing, since the area of plastoglobuli of chloroplast area increased (data not shown), which is known to be an indication of ageing (Hudak, 1981). The pattern of thylakoid organization at level $2(110 \mathrm{~cm}$ aboveground) was similar to that at level 1; only the appressed/non-appressed membrane ratio was initially somewhat higher than at level 1.

Leaves at level 3 maintained high rates of $\mathrm{CO}_{2}$ uptake throughout the $7 \mathrm{wk}$ period under examination (Fig. 2A), although the quantum flux density decreased markedly (Fig. 2B). The thylakoid structure was typical of sunny habitats, since the ratio of the length of appressed to non-appressed thylakoid membranes remained below 1.4 (Fig. 1B). The leaves examined from levels 4 and 5 were physiologically young and the rates of $\mathrm{CO}_{2}$ uptake recorded were from intermediate to high (Fig. 2A). The ratio of the length of appressed to non-appressed thylakoid membranes was, however, quite different (Fig. 1B). One might speculate that the high ratio, 1.5 , in chloroplasts at level 4 was due to the late season, as suggested by Aro et al. (1985). This argument is, however, not valid for the somewhat younger leaves at level 5, which had developed under similar climatic conditions but had a lower rate of $\mathrm{CO}_{2}$ uptake and an appressed/non-appressed membrane ratio of about 1 .

In the present study, a negative correlation was found between $P_{\mathrm{N}}$ and the ratio of the length of appressed to nonappressed thylakoid membranes (Fig. 2A) and between the ratio of the length of appressed to non-appressed thylakoid membranes and photon fluence rate (Fig. 2B). This suggests that, in the canopy, acclimation of the thylakoid structure to decreasing photon fluence rates will lead to gradual impairment of the photosynthetic capacity.

\section{References}

Anderson J.M. \& Osmond C.B. (1987) Shade-sun responses: compromises between acclimation and photoinhibition. In: Photoinhibition. (Kyle D.J., Osmond C.B. \& Arntzen C.J., eds.), Elsevier Science Publishers B.V., Amsterdam, pp. 1-38

Aro E.M., Korhonen P., Rintamäki E. \& Mäenpää P. (1985) Diel and seasonal changes in the chloroplast ultrastructure of Deschampsia flexuosa (L.) Trin. New Phytol. 100, 537-548

Aro E.M., Rintamäki E., Korhonen P. \& Mäenpää P. (1986) Relationship between chloroplast structure and $\mathrm{O}_{2}$ evolution rate of leaf discs in plants from different biotopes in south Finland. Plant Cell Environ. 9, 87-94

Boardman N.K. (1977) Comparative photosynthesis of sun and shade plants. Annu. Rev. Plant. Physiol. 28, 355-377

Hudak J. (1981) Plastid senescence. 1. Changes of chloroplast structure during natural senescence in cotyledons of Sinapis alba $\mathrm{L}$. Photosynthetica 15, 174-178

Lichtenthaler H.K., Buschmann C., Dōl M., Fietz H.J., Bach T., Kozel U., Meier D. \& Rahmsdorf U. (1981) Photosynthetic activity, chloroplast ultrastructure, and leaf characteristics of highlight and low-light plants and of sun and shade leaves. Photosynth. Res. 2, 115-141

Vapaavuori E.M. (1986) Correlation of activity and amount of ribulose 1,5-bisphosphate carboxylase with chloroplast stroma crystals in water-stressed willow leaves. J. Exp. Bot. 37, 89-98 